\title{
SOME EXTRACTS FROM THE HISTORY OF ENTOMOLOGY IN CHINA
}

\section{By Gaines LiU}

Biological Laboratories, Harvard University

The following extracts are of historical interest only. They are published here, not in the spirit of questioning the scholarship of those whose work I shall mention, but to render available some of the historical facts to those who might care to have them but who are handicapped by language difficulties. My point can be better explained by a very good instance. In a book, called Chow $\mathrm{Li}$, one of the 13 Classics published long before the Christian era, we find a detailed account of a "Bureau of Entomology" which would be considered well organized even under our modern standard. Yet China is not even mentioned by Dr. L. O. Howard, one of the best known and the most respected entomologists of the world today, in his "History of Applied Entomology". It is very plain in this case that the whole trouble is due to an inability to consult Chinese literature. Later on I shall publish a note on this ancient "Bureau of Entomology". For the present I should like to add some information to supplement the following books, namely:

1. The Biological Control of Insects, by H. L. Sweetman, 1936.

2. The Insect Singers, by J. G. Myers, 1929.

3. Entomology, by J. A. Folsom and R. A. Wardle, 1934.

1. The Biological Control of Insects-Earliest Record ca. 889-903.

This book appeared in 1936. I ordered it last year when I was in China but the war came earlier than the book, and it was only lately that I had the pleasure of making the ac- 
quaintance of this excellent work. On the first page, Dr. Sweetman writes as follows:

"The first written record we have of the movement of beneficial insects is that of Forskål (1775). He states that the date palms in Arabia were attacked by ants, which often destroyed the trees. The growers introduced colonies of predatory ants annually from the mountains and these controlled the pest species."

Dr. Sweetman is well aware of the practice of using ants in pest control in that part of the world, for immediately he writes that "the use of ants for the protection of orchards from insect pests is a practice of long standing in various Asiatic countries, and is still employed today". To this, based upon my personal field data, I quite agree and I can add a few more uses of the ants and some other forms of biological control of insects as practiced in my country. But what concerns us now is the "first written record". The following is a translation of a Chinese record.

"There are many kinds of ants in Lingnan (South China). Sometimes one finds that the ants are carried in a bag and sold on the market. The ants are yellow with long legs, larger than ordinary ants and live in a nest made from leaves and twigs. They are bought for the protection of the orange for it is said that without these ants most of these fruits would be wormy."

This record is contained in a book called Ling Pio Lu Yi or Wonders from South China by Liu Shun. There is no way to tell when this book was published. We know, however, that the author served as an army officer in Kwangtung during the reign of Tsao Chung of Tang (889-903) and the time must have been near the end of the 9 th or the beginning of the 10th century. The same fact was mentioned in "Book on Tree Planting" by Yu Tsung Ben, a writer from the Yuan Dynasty (1280-1368). Thus Dr. Sweetman will be glad to know that the written records of insect control really go back much earlier. The ants in question were determined, according to the correspondence I have had with Prof. W. E. Hoffmann of Lingnan University, Canton, as CEcophylla smaragdina Fab. and were determined probably by the late Professor Wheeler. Today in Canton nests of these ants may be bought for about one silver dollar each. 
2. The Insect Singers - "Chu Ki” is Lycorma not Huechys.

Although this book was published in 1929, I had not seen it until recently when I came to work on the cicadas I brought from China. Dr. Myers, the author, has given us a handy and readable book on the natural history of these insects. What interests me particularly are those occasions where he speaks on cicadas in China. Here it gives me the impression that, being unable to get at the original sources and consequently relying on what others have to say, Dr. Myers, in some cases, unfortunately subscribed as an innocent victim to those mistakes committed by others.

For instance on page 3 he states, "the mention of cicadas apparently does not occur until the authoritative edition, the Pen Ts'ao Kang Mu, of A.D. 1578." The author gives one the impression that the cicadas were not mentioned until 1578 while what he really means, if I interpret correctly, is that they were not mentioned in the Pen Ts'ao. In either case, however, if one is able to read Chinese he will find that this is not correct. He will discover, for instance, many references to these insects both in the $\mathrm{Li}$ Chi or Book of Rites and the Shih Ching or Book of Odes as these two Classics are respectively known in English. This would mean that the earliest mention occurs at least not later than 500 B.C. because these two Classics were connected in one way or another with Confucius (551-479 B.C.). In short, Dr. Myers has been entirely deceived by the Japanese version.

On page 23, Dr. Myers writes: "the cicada itself was labelled Tchen, while the nymph-the tettiometra or cicada mother, of the Greek-Tchen touy, i.e. the cicada with a skin which falls like that of a serpent." Here we have another mistake that can easily be rectified if one knows Chinese. Tchen touy is the shed skin. How it came to be interpreted as "nymph" is abstruse because "touy" means shed and the shed skin of cicada is the form generally mentioned as a drug in the Chinese pharmacopoeia.

That Chu ki is a Lycorma (L. delicatula White), a fulgorid common in north China, not Huechys sanguinea De Geer, has never been suspected ever since the day when Amyot created the genus Huechys in 1836. It was fully accepted 
by Distant in his Monograph of Oriental Cicadidae (1892) and Dr. Myers of course could not avoid the pitfall. I know that chu ki is Lycorma but I had not associated chu ki with Huechys until I read Myers' book (p. 22), although I have always tried to identify Huechys in Chinese ever since I learned from Distant that this insect is employed by the Chinese as a drug. Now it is clear that Huechys is a direct romanization of the Chinese term chu ki.

There are several ways to prove that chu ki is L. delicatula and not Huechys sanguinea. "Ki" means a "fowl" and the general form of a Lycorma resembles a fowl while the form of a Huechys does not. On the other hand, Huechys is a southern species, and becomes rare as we approach the Yangtze valley. Among the large number of specimens collected, I have only a single specimen from Wuchang and another one from Ichang (two new records for this species) while all the old specimens in the Harvard collection came from south China. The case with Lycorma seems to be just reverse. Although delicatula is known as far south as India, it is not so common in the south as in the north, although the south has its own species. Now all the writers of the Chinese Pen Ts'ao were people from the north. It seems to be more reasonable to assume that the insect in question is a northern species instead of a southern one. But the best proof is found in the description of chu ki as it was given by various medical men and for this I submit the following translation.

"These insects are very common in Honan. They look like a moth but with the abdomen larger and the head and the legs blackish. There are two pairs of wings, the outer pair (tegmina) is grey while the inner pair (wings) is deep red, decorated with all five colors"-from Pen Ts'ao Yen Yi by Kio Chung Pi (1111-1116). ${ }^{1}$

"The chu are the ill-smelling Ailanthus trees. The outer wings of the insects (chu ki) are greyish yellow while the inner ones are decorated with all five colors. They generally line up on the tree and by the late fall, deposit their eggs on the bark. The nymph has six legs, with wings (?) doubled and black and the head depressed and truncated in front."From Pen Ts'ao Kang Mu by Li Shih Chen (1578).

${ }^{1}$ This is the period with which the name of the author is connected. 
The "greyish yellow" is very accurate for those specimens I have from Peiping. From these descriptions, it is evident that chu ki is Lycorma and not Huechys. ${ }^{2}$ Huechys, the black cicada with a red head, is called "Er", according to Fang Yen, another Chinese Classic appearing long before the Christian era.

In closing I have one other statement to make for those who are interested in biological problems in ancient China. Based upon my personal experience, obtained in preparing a "History of Entomology in China", a work encouraged by Professor C. T. Brues and Dr. G. Sarton, I have found that the earlier Chinese as a whole were quite vague in their expression. Exactly the same term may mean entirely different things to different authors and sometimes it is very difficult to distinguish them unless one has as a general background some knowledge of the fauna and flora of the region whence the author came. Thus it is not even safe to trust the translation of those who know Chinese unless they are duly qualified from a biological standpoint.

\section{Entomology - Fireflies as Imperial Entertainment in China.}

The following paragraph from Folsom and Wardle, page 521 , is very interesting to me.

"Annually the people of Gifu collect many thousands of fireflies which are sent to Tokio and on a certain night are liberated for the enjoyment of the emperor."

This paragraph is interesting to me because it reminds me of the following story about one of the romantic emperors of China.

"In the 12th year of Da Yeh (616), emperor Yang visited the Ching Hua Palace. Bushels of fireflies were collected by imperial order. In the evening, the Emperor and his courtiers went up the mountain. The fireflies were then released and the whole valley became immediately enlivened with the sparklings of these insects."-Sui Shu or Annals of the Dynasty of Sui.

\footnotetext{
2For detailed description of these two insects, see page 157 (Huechys sanguinea De Geer) and page 207 (Lycorma delicatula White) in Distant, Fauna British India, Rhynchota, Vol. 3, 1906.
} 
Whether the Japanese custom was introduced from China, we do not know. Japan did send a large number of students to China during the Tang Dynasty (618-907). The fireflies are still one of the best evening entertainments the Chinese children have today. Mothers are generally requested by their children to save their empty egg-shells in which the youngsters house their catch and watch the flashing in the dark when they go to bed. 

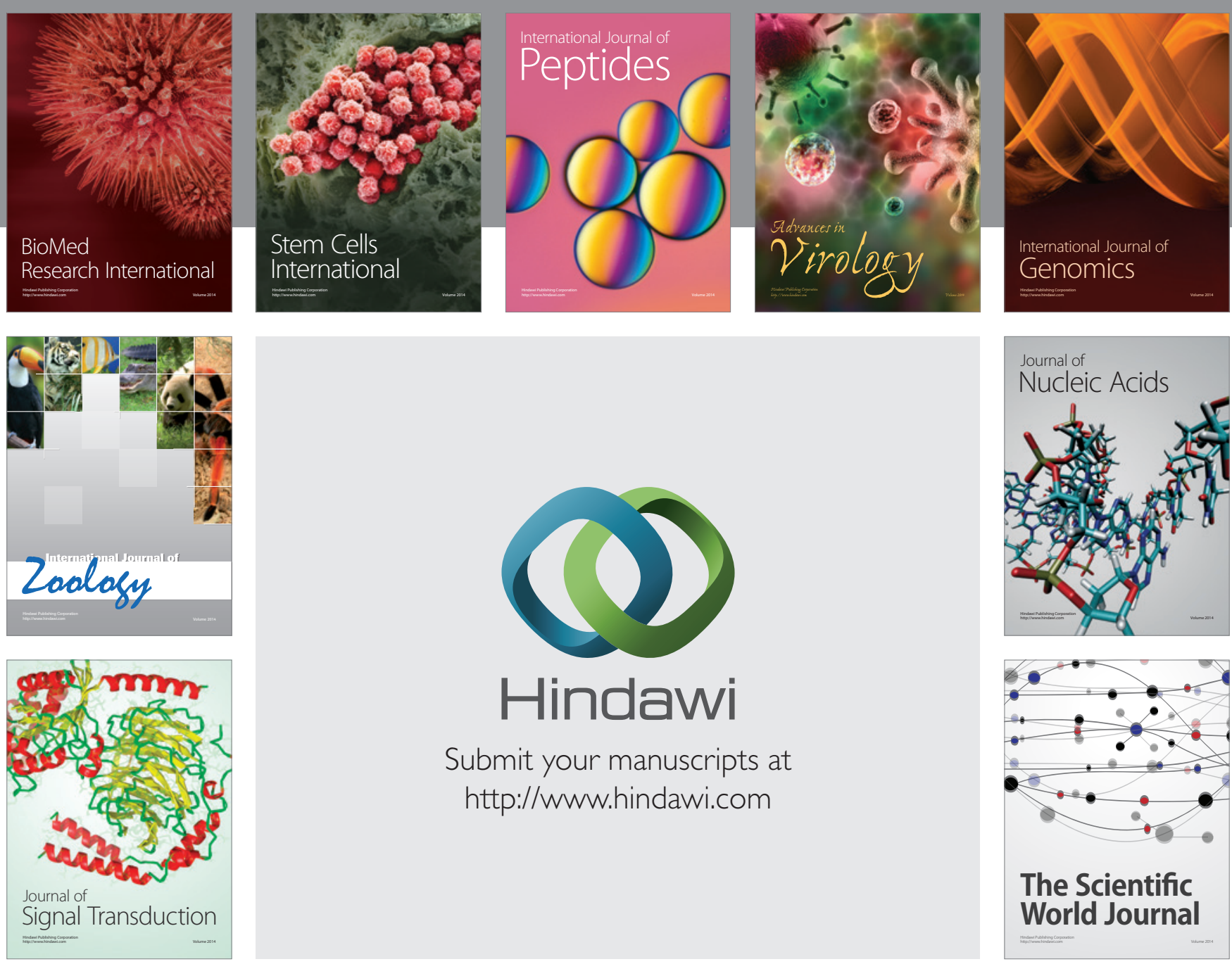

Submit your manuscripts at

http://www.hindawi.com
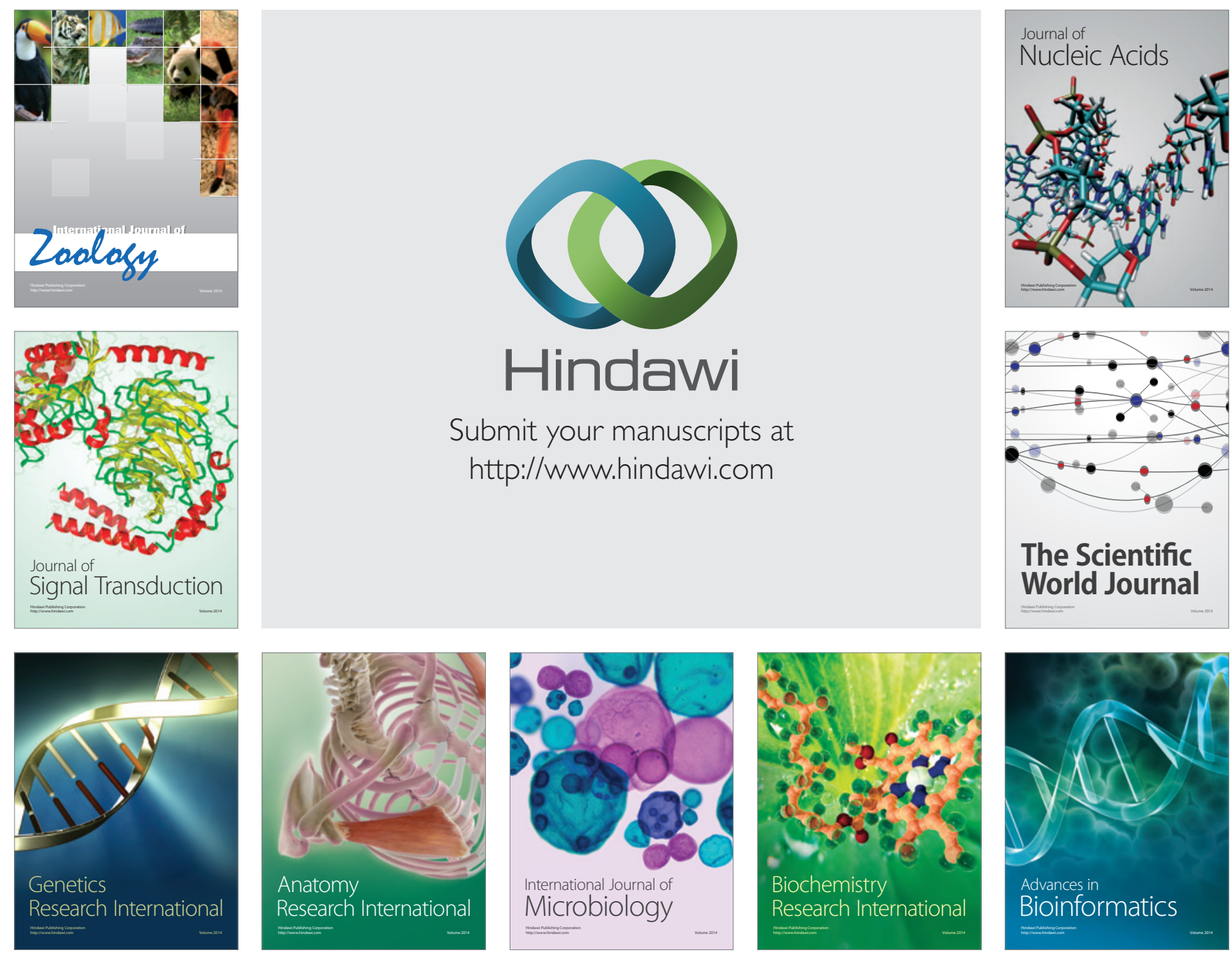

The Scientific World Journal
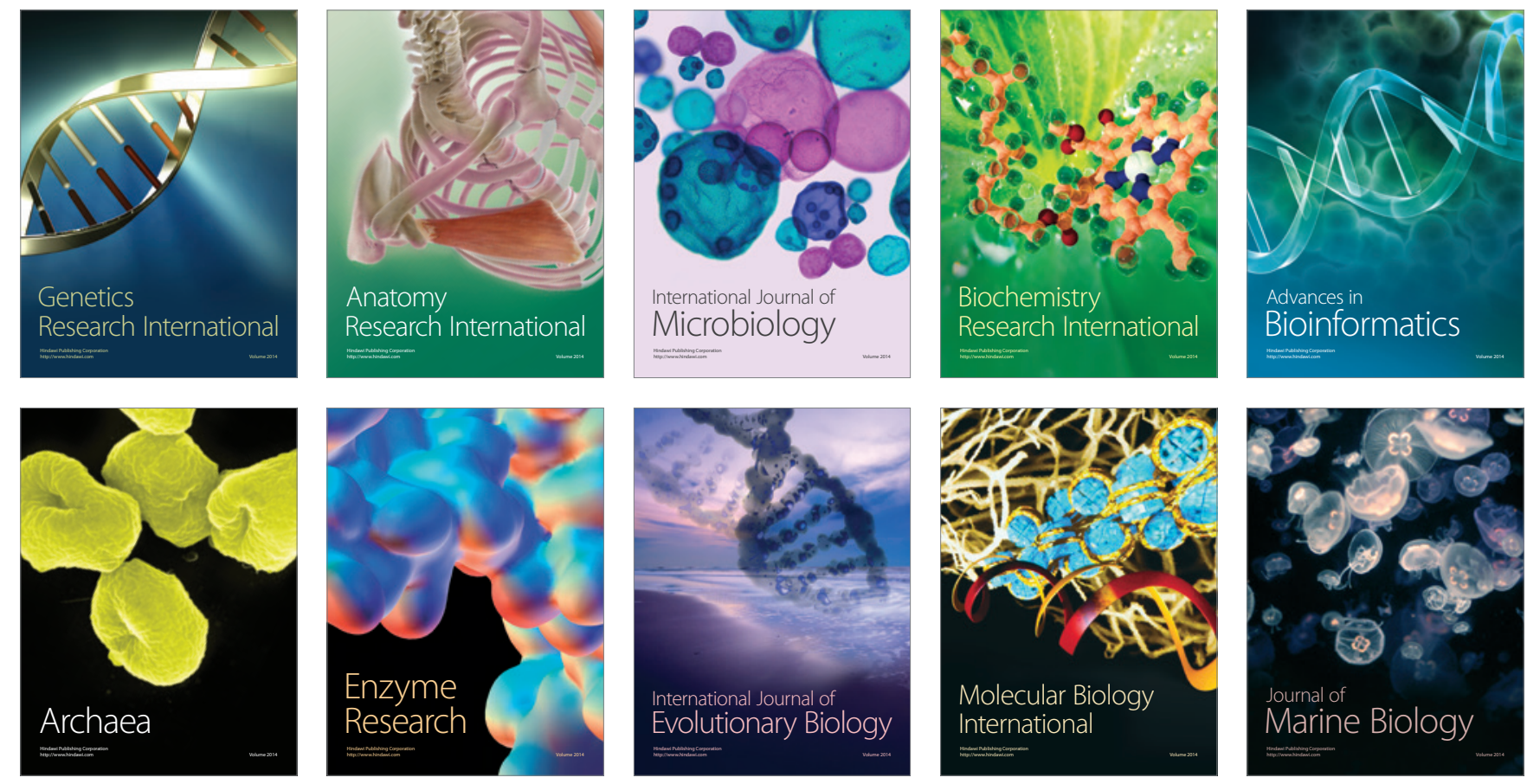